\title{
Vapor-phase protection of steel by inhibitors based on salts of higher carboxylic acids ${ }^{1}$
}

\section{O.A. Goncharova, A.Yu. Luchkin, I.A. Archipushkin, N.N. Andreev, * Yu.I. Kuznetsov and S.S. Vesely}

A.N. Frumkin Institute of Physical Chemistry and Electrochemistry, Russian Academy of Sciences, Leninsky pr. 31, 119071 Moscow, Russian Federation

*E-mail: $\underline{\text { n.andreev@mail.ru }}$

\begin{abstract}
It has been shown that it is possible to create a technology for efficient protection of steel items by short-term treatment in vapors of low-volatile corrosion inhibitors in specialized chambers at elevated temperatures. A combination of physical (XPS), electrochemical (potentiodynamic polarization, electrochemical impedance spectroscopy) and corrosion methods (recurrent moisture condensation on specimens in laboratory as well as outdoor tests) was used to study the properties of adsorption films formed on steel in vapors of higher carboxylic acids (stearic, oleic and linolenic), polyamine A, and their mixtures. It was found that carboxylic acids and the polyamine synergistically enhance the protective aftereffect of each other. The protective aftereffect of the mixed inhibitors studied depends on the temperature of metal treatment and is the longest after treatment at $120^{\circ} \mathrm{C}$. Upon one-hour treatment of steel with mixed chamber inhibitors at this temperature, nano-sized adsorption layers are formed on steel. They inhibit corrosion processes under the model conditions and provide a long-term protection of steel from atmospheric corrosion in outdoor tests.
\end{abstract}

Keywords: atmospheric corrosion, steel, temporary protection, chamber corrosion inhibitors, nano-sized protective films.

Received: June 1, 2019. Published: August 6, 2019

doi: $\underline{10.17675 / 2305-6894-2019-8-3-9}$

\section{Introduction}

The protection of metal items from atmospheric corrosion is a technical problem of major importance [1-3]. Corrosion inhibitors, including vapor phase ones, are widely used to solve it [3-6]. The latter compounds are a subject of close attention from researchers [614]. One of the varieties of vapor-phase inhibitors are the so-called "chamber" inhibitors (ChIn) [14-25]. The protection of metal items by these inhibitors is performed by short treatment of metals in a closed space (chamber) with vapors of organic inhibitors that are

\footnotetext{
${ }^{1}$ This study was financially supported by the Russian Science Foundation (RSF) Grant no.17-13-01413 "Fundamental aspects of formation of ultrathin passivating films from organic compounds in protection from atmospheric corrosion".
} 
low-volatile under standard conditions, at elevated temperatures $(t)$ where the vapor pressure of compounds increases by several orders of magnitude.

In the course of such a "chamber" treatment (CT), at an optimal choice of compounds, duration of contact of their vapor with metals and temperature, thin films are formed on the surface. These films have a long protective aftereffect (PAE) and slow down the initiation and development of corrosion by a factor of dozens or even hundreds.

The capabilities of the chamber method were demonstrated for the protection of steel, zinc and copper by ChIn of various kinds [14-23].

In this paper, we deal with the properties of adsorption films formed on steel upon CT in vapors of higher carboxylic acids, viz., stearic (SA), oleic (OLA), linolenic (LA), as well as polyamine $\mathrm{A}(\mathrm{PA})$ and their mixtures.

\section{Experimental}

All the reagents used in this study were of "pure" grade.

Samples and electrodes of St3 low carbon steel were used in the experiments. Flat specimens had dimensions of $30 \times 50 \times 1 \mathrm{~mm}$. Each specimen had a hole for mounting in test cells and chambers. Cylindrical electrodes were $10 \mathrm{~mm}$ in diameter. One of their buttends had a hole with threading for the mounting rod. Electrodes were embedded in Teflon shells in order to prevent the interaction of their side surfaces with the electrolyte during the tests. The lower butt-end of the cylinder served as the working surface.

Before treatment of specimens and electrodes with ChIn vapors, their working surfaces were cleaned with sandpapers with decreasing grain sizes, degreased with acetone and dried. Further, the specimens were mounted in $0.5 \mathrm{~L}$ sealed glass vessels containing a weighed portion of a ChIn $(0.5 \mathrm{~g})$. The vessels were placed into a heated drying chamber. The metal was treated with inhibitor vapors for $1 \mathrm{~h}$. After exposure in the chamber, the vessels were removed, allowed to cool to room temperature and kept for one day. The specimens were then withdrawn and tested.

The PAE of heat treatment of the metal in ChIn vapors was evaluated in corrosion tests (with intense moisture condensation and in outdoor tests) and in electrochemical (potentiodynamic and $\mathrm{AC}$ impedance) experiments.

In the tests with recurrent moisture condensation, the specimens were hung on nylon fibers on the lids of airtight glass cells. The volume of each cell was $600 \mathrm{ml}$. Hot water $\left(50^{\circ} \mathrm{C}, 100 \mathrm{ml}\right)$ was poured into each cell. Once every 24 hours, each cell was opened and the cold water was replaced with hot water. Water replacement was combined with visual inspection of the specimens. During the first 12 hours of exposure, the specimens were inspected once every hour without opening the cells.

In outdoor corrosion tests, the specimens were exposed at the Moscow corrosion station under a shelter preventing direct exposure to atmospheric precipitation. The specimens were inspected once a month. The total test duration was 4 months.

The potentiodynamic experiments were performed using an IPC-pro potentiostat (RF) and a standard three-electrode cell with divided electrode spaces. A platinum wire served 
as the auxiliary electrode. The potentials $(E)$ were measured against a saturated silver/silver chloride reference electrode and converted to the normal hydrogen scale. The experiments were carried out in borate buffer solution ( $\mathrm{pH}$ 7.36) containing $0.001 \mathrm{M}$ sodium chloride. The electrodes were placed into a cell containing the electrolyte, kept for 5 minutes and polarized from the established potential $\left(E_{\text {start }}\right)$ in anodic and cathodic directions. The potential sweep rate was $0.2 \mathrm{mV} / \mathrm{s}$.

Anodic polarization was performed to a potential that exceeded the breakdown potential $\left(E_{\mathrm{br}}\right)$ by $0.005-0.010 \mathrm{~V}$. Local depassivation of the metal was detected by a sharp increase in the anodic current density $(i)$ or current oscillations. In some cases, the test was interrupted right after oscillations on anodic polarization curves began, in order to confirm that pits had formed by visual inspection. The local depassivation potentials $\left(E_{\mathrm{ld}}\right)$ and the "counter-pitting basis" ( $\left.\Delta E=E_{\mathrm{ld}}-E_{\text {start }}\right)$ were used as the criteria of protective effect.

Cathodic polarization was interrupted at $E=-0.5 \mathrm{~V}$.

Electrochemical impedance spectra were obtained using a potentiostat of the same brand and a Frequency Response Analyzer (FRA, produced in RF). The experiments were performed in a cell similar to that used in the potentiodynamic experiments. Similarly, a silver/silver chloride reference electrode and a platinum auxiliary electrode were employed, and borate buffer solution with $\mathrm{pH} 7.36$ containing $0.001 \mathrm{M}$ sodium chloride was used as the electrolyte. The electrodes were placed into a cell with the electrolyte and kept for 5 min before the measurements that were performed at the open circuit potential. The frequency was varied within $0.1-10^{5} \mathrm{~Hz}$.

To calculate the electrochemical impedance parameters, the equivalent circuit shown in Figure 1 was used.

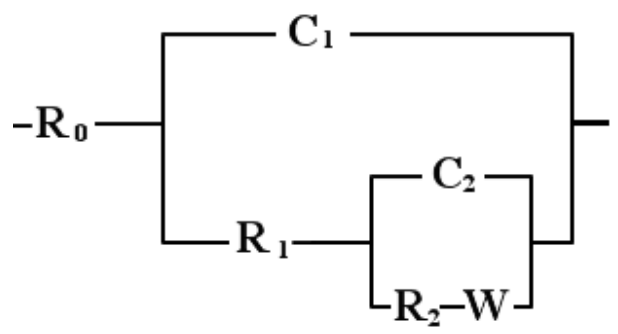

Figure 1. The equivalent circuit for calculating the impedance parameters.

Here $R_{0}$ is the solution resistance; $C_{1}$ and $R_{1}$ are the capacitance and resistance of the double electric layer, respectively; $C_{2}$ and $R_{2}$ are similar parameters characterizing the oxide layer; and $W$ is the Warburg impedance.

The results were processed and impedance parameters were determined using Dummy Circuits Solver software, version 2.1. The fit between the experimental and calculated data was no worse than $98 \%$.

The degree of steel electrode protection was calculated using the formula:

$$
Z=\left(\Sigma R_{\text {inh }}-\Sigma R_{\text {bg }}\right) / \Sigma R_{\text {inh }} \cdot 100 \%
$$


where $R_{\mathrm{bg}}$ and $\mathrm{R}_{\mathrm{inh}}$ are the total resistances of "steel-electrolyte" interphase interaction, including $\mathrm{R}_{1}, \mathrm{R}_{2}$ and $\mathrm{W}$, after thermal treatment of the electrode in the absence and in the presence of a ChIn, respectively.

The thickness of the films $(d)$ formed on the metals during the CT was estimated by analyzing the X-ray photoelectron spectra (XPS). The C1s, O1s, N1s and Fe2p electron spectra were recorded on an Omicron ESCA+ instrument (Germany) with a Mg anode as the radiation source. The pressure in the analyzer chamber did not exceed $10^{-9}$ Torr. The analyzer energy was $20 \mathrm{eV}$. The positions of the lines of the elements that constitute the surface layer was standardized by the C1s peak whose energy was assumed to be $285.0 \mathrm{eV}$. The peak intensity was obtained after subtracting the background by the Shirley method [24]. The thicknesses of the layers formed on the surface were calculated using the MultiQuant 7.70 program [25], taking into account the photoionization cross-sections of atoms [26] and the electron mean free paths [27].

\section{Experimental Results and Discussion}

The results of corrosion tests with recurrent moisture condensation on the samples are presented in Table 1. In these experiments, the effect of temperature of steel treatment with ChIn on the PAE of adsorption films was studied.

Table 1. Effect of the temperature of adsorption film formation on the results of corrosion experiments with recurrent moisture condensation on the samples.

\begin{tabular}{|c|c|c|c|c|}
\hline \multirow{2}{*}{ ChIn } & \multicolumn{4}{|c|}{ Protection time (in hours) at treatment temperature: } \\
\hline & $80^{\circ} \mathrm{C}$ & $100^{\circ} \mathrm{C}$ & $120^{\circ} \mathrm{C}$ & $140^{\circ} \mathrm{C}$ \\
\hline Without ChIn & 0.5 & 1.0 & 1.0 & 1.5 \\
\hline SA & 1.0 & 1.0 & 4.0 & 5.0 \\
\hline OLA & 1.0 & 1.0 & 1.0 & 4.0 \\
\hline LA & 1.0 & 1.0 & 3.0 & 3.0 \\
\hline PA & 1.0 & 1.0 & 2.0 & 4.0 \\
\hline $\mathrm{SA}+\mathrm{PA}$ & 1.0 & 2.0 & 504 & 504 \\
\hline $\mathrm{OLA}+\mathrm{PA}$ & 1.0 & 4.0 & 672 & 504 \\
\hline $\mathrm{LA}+\mathrm{PA}$ & 1.0 & 2.0 & 504 & 504 \\
\hline
\end{tabular}

On the specimens heat-treated without a ChIn, a reddish rust deposit appeared soon after hot water was introduced into the cell. The incubation time of corrosion varied from 0.5 to $1.5 \mathrm{~h}$ and, in fact, did not depend on the temperature of metal treatment.

Chamber treatment of steel in the presence of carboxylic acids and PA (as individual compounds) prolonged the time until the appearance of corrosion up to 3 -fold. In this case, the PAE of the films formed by these compounds slightly increased with increasing temperature. Like in the absence of CIN, general corrosion was observed. 
The PAE of surface films obtained from mixtures of the carboxylic acids studied with PA increased, albeit weakly, in the $t$ range from 80 to $100^{\circ} \mathrm{C}$. However, an increase in $t$ to $120^{\circ} \mathrm{C}$ increased the PAE by a factor of hundreds. Corrosion initiation after $\mathrm{CT}$ at this temperature slowed down by a factor of more than 500 for SA+PA and LA+PA mixtures. This factor reached 672 for the OLA+PA formulation. Thus, the components of mixtures showed a pronounced synergistic effect. The PAE of the most efficient formulation, OLA+PA, was 4 times higher than that of the previously studied ChIn based on a mixture of benzotriazole with octadecylamine [19].

An increase in CT temperature to $140^{\circ} \mathrm{C}$ was not accompanied by an additional protection improvement. What is more, the temperature dependence of PAE for the $\mathrm{OLA}+\mathrm{PA}$ mixture had a maximum at $120^{\circ} \mathrm{C}$. We observed similar extremal dependences of PAE on CT temperature on metals previously as well [15-23]. They are due to an interaction of two processes which oppositely affect the adsorption of ChIn vapors. On the one hand, the vapour pressure of inhibitors grows with an increase in $t$, which favors the adsorption of their vapors. On the other hand, as $t$ rises, the adsorption of vapors on solid sorbents becomes weaker.

It is significant that as the PAE of adsorption films of the composite ChIn studied increases, the nature of corrosion changes. When it is initiated, point corrosion sites appear on the metal, the number and area of which do not change upon further exposure of metal samples in the corrosive environment.

Thus, like in $[17,19], 120^{\circ} \mathrm{C}$ is the optimal temperature of steel chamber treatment for the inhibitors studied. In view of this, in all subsequent experiments, this temperature was used to create the adsorption films of inhibitors.

The high PAE of the composite ChIn studied is confirmed by the results of electrochemical studies. Figure 2 shows the anodic and cathodic polarization curves of steel electrodes after treatment with ChIn vapors at $120^{\circ} \mathrm{C}$.

CT weakly affected the $E_{\text {start }}$ of steel electrodes. Its variation range was from $0.055 \mathrm{~V}$ (in the case of steel CT by vapors of the OLA+PA mixture) to $0.135 \mathrm{~V}$ (with the LA+PA mixture).

The cathodic polarization curves were characterized by an extended region (up to $0.2 \mathrm{~V}$ ) where the cathodic current density $i$ only slightly depended on $E$. It was followed by a region of cathodic current density growth where reduction of the surface oxide occurred. This region changed to an anodic loop associated with the active dissolution of the metal. Further $E$ scanning in the cathodic direction again resulted in an increase in cathodic current density.

The values of active dissolution current density of steel samples that did not undergo CT with inhibitor vapors reached $0.05-0.06 \mathrm{~mA} / \mathrm{cm}^{2}$. All the ChIn that we studied inhibited active dissolution by a factor of 2 or more. The highest protective effects were provided by films formed in OLA or LA vapors $\left(i<0.01 \mathrm{~mA} / \mathrm{cm}^{2}\right)$, whereas the smallest effects were observed on steel treated with vapors of PA or the LA+PA mixture. 


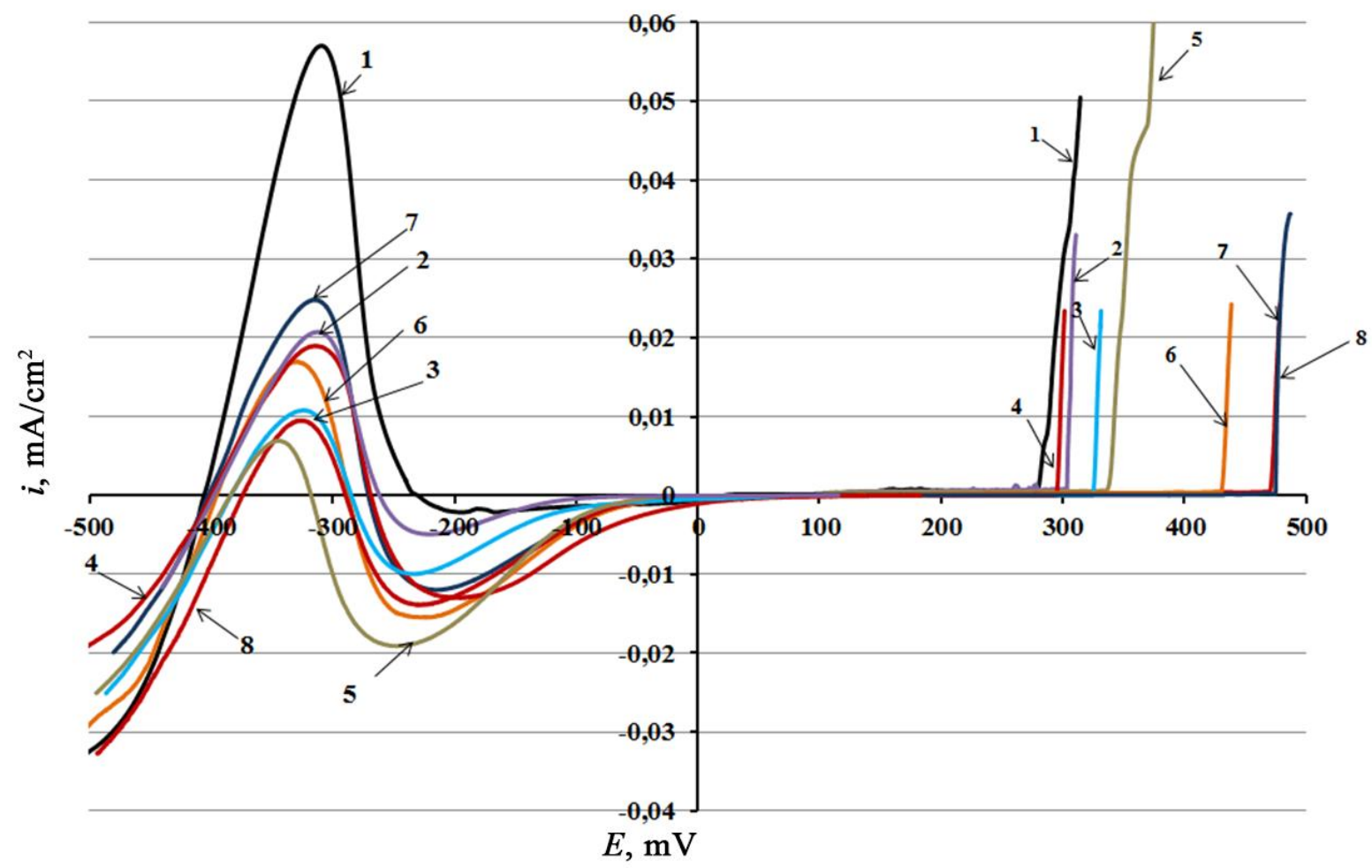

Figure 2. Polarization curves of $\mathrm{St} 3$ in borate buffer solution ( $\mathrm{pH} 7.36$ ) containing $0.001 \mathrm{M}$ NaCl. 1 - without a ChIn; 2 - PA ; 3 -SA; 4 - LA; 5 - OLA; 6 - SA + PA; 7 - LA + PA; $8-$ OLA + PA .

The characteristics of anodic polarization curves of steel electrodes are summarized in Table 2. Their shapes are characteristic of passive steel. Anodic polarization of electrodes that underwent heat treatment without a ChIn and treated in PA vapors or its mixtures with carboxylic acids did not lead to a noticeable increase in $i$ up to $E_{\mathrm{ld}}$. Upon reaching the latter, oscillations appeared on the curves due to the initiation and repassivation of local depassivation sites. Visual inspection of the electrodes extracted from the electrolyte after the oscillations began confirmed this assumption. Small pits were visible on the steel surface through a magnifying glass. Further polarization resulted in breakdown of the passive film and an abrupt $i$ growth. In this case, one or more local dissolution sites visible by unaided eye formed on the metal. It is significant that the reproducibility of $E_{\mathrm{br}}$ between the tests was rather poor.

No current oscillations were recorded on the curves of anodic polarization of steel treated with carboxylic acid vapors. The passivity region was immediately followed by a sharp increase in $i$.

All the ChIn studied slowed down the local depassivation of steel to a different extent, which manifested itself in an $E_{\mathrm{ld}}$ ennoblement and a $\Delta E$ growth. At the same time, the polarization measurements, like the corrosion experiments, indicate a higher PAE of surface films formed by mixed ChIn. In fact, the passive region of electrodes treated with 
the most effective mixture, OLA+PA, was $0.38 \mathrm{~V}$, i.e., almost 40 times larger than the $\Delta E$ of the background samples.

Table 2. Effect of steel treatment in ChIn vapors on the characteristics of anodic polarization curves.

\begin{tabular}{ccccc}
\hline ChIn & $\boldsymbol{E}_{\text {start }}, \mathbf{V}$ & $\boldsymbol{E}_{\mathbf{l d}}, \mathbf{V}$ & $\boldsymbol{\Delta} \boldsymbol{E}, \mathbf{V}$ & $\boldsymbol{E}_{\text {br }}, \mathbf{V}$ \\
\hline Without ChIn & 0.095 & 0.105 & 0.010 & 0.280 \\
SA & 0.090 & 0.325 & 0.235 & 0.325 \\
OLA & 0.105 & 0.335 & 0.230 & 0.335 \\
LA & 0.090 & 0.290 & 0.200 & 0.290 \\
PA & 0.120 & 0.225 & 0.105 & 0.300 \\
SA+PA & 0.095 & 0.395 & 0.300 & 0.430 \\
OLA+PA & 0.055 & 0.435 & 0.380 & 0.475 \\
LA+PA & 0.135 & 0.395 & 0.260 & 0.470 \\
\hline
\end{tabular}

The electrochemical impedance spectra shown in Fig. 3 in the form of Nyquist plots also indicate a high PAE of films formed in vapors of mixed ChIn.

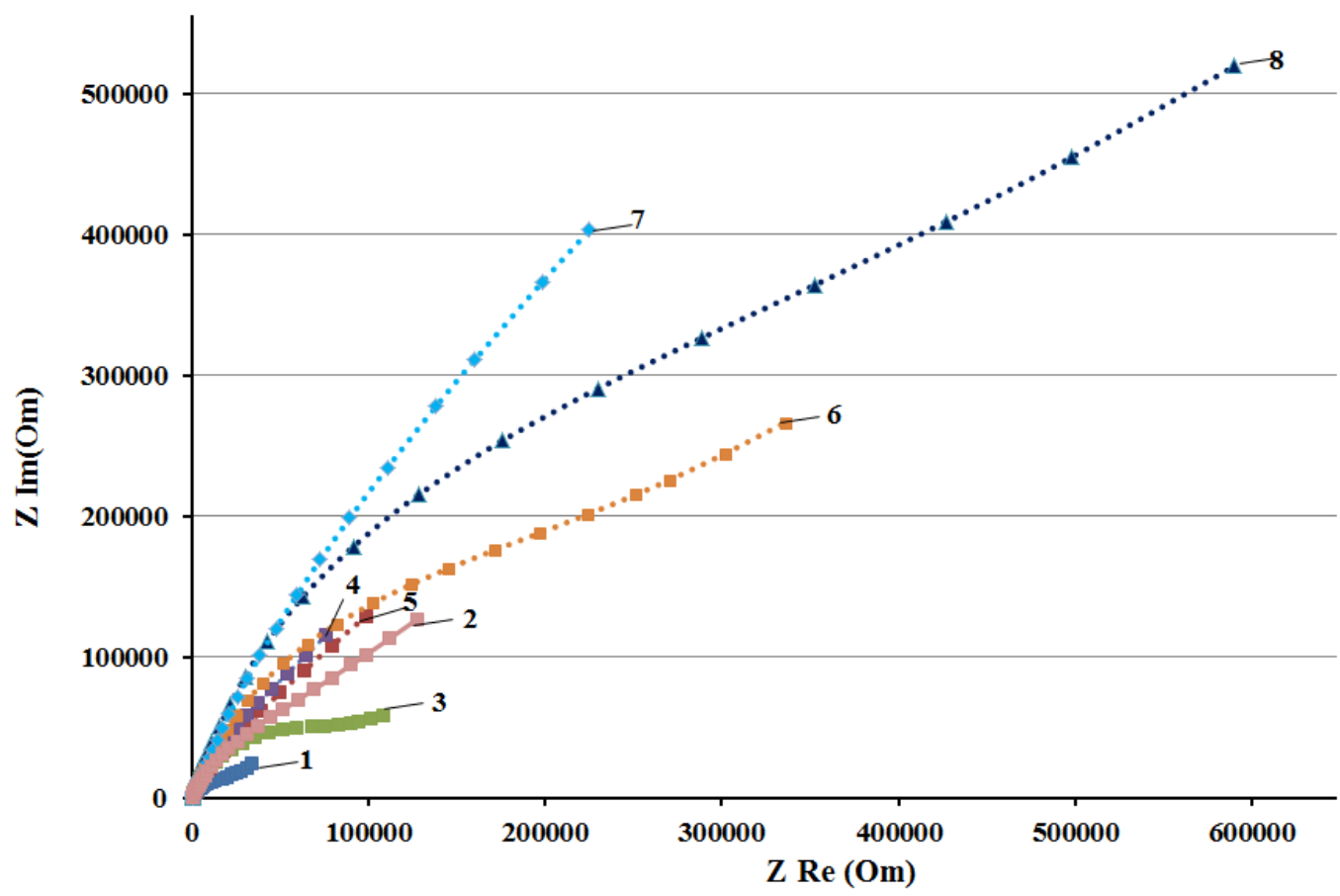

Figure 3. Nyquist plots of steel electrodes after $\mathrm{CT}$ in the absence of an inhibitor -1 , or in the presence of: 2 - PA ; 3 -SA; 4 - LA; 5 - OLA; 6 - SA + PA; 7 - LA + PA; 8 - OLA + PA.

Two regions can be distinguished in the hodograph of a steel electrode heat-treated without ChIn. The first one in the frequency range from $100 \mathrm{kHz}$ to $10 \mathrm{~Hz}$ is a semicircle typical of systems with kinetically controlled charge transfer. The second one in the region 
of lower frequencies, from 0.1 to $10 \mathrm{~Hz}$, is a straight line at an angle of $45^{\circ}$ characteristic of diffusion processes.

Electrode treatment with ChIn did not change the shape of the hodographs that were described by the same equivalent circuit. In this case, the capacitance $C_{2}$ and resistance $R_{2}$ characterized the total of the oxide and inhibitor layers. Linearization of the hodographs of ChIn-treated electrodes was observed at lower frequencies (from 1 to $0.1 \mathrm{~Hz}$ ) than for the reference sample.

CT in vapors of OLA, LA and PA increased $R_{1}$ and $R_{2}$ 1.2-2-fold and $W 5-7$-fold (Table 3). This results from hindrance of diffusion processes due to the formation of an inhibitor layer on the surface. Upon steel treatment with SA vapors, the $W$ values increased to a smaller extent ( $\sim$-fold) than the $R_{1}$ and $R_{2}$ values (3.3- and 5.5-fold, respectively). In all cases of $\mathrm{CT}$, the $C_{1}$ and $C_{2}$ values decreased, although slightly, which is a consequence of ChIn adsorption on the steel surface.

For mixed ChIn, the characteristic electrode parameters changed more considerably. The values of $R_{1}, R_{2}$ and $W$ became dozens of times larger after CT. Conversely, the values of $C_{1}$ and $C_{2}$ decreased by more than an order of magnitude.

The $Z$ values calculated from the data in Table 4 indicate a high $(Z>91 \%)$ anticorrosive efficiency of ChIn based on mixtures of higher carboxylic acids and PA. In this case, the maximum $Z(95.1 \%)$ was observed for electrodes treated with a mixed ChIn based on OLA.

Table 3. Impedance parameters calculated for steel electrodes that underwent various variants of chamber treatment.

\begin{tabular}{cccccccc}
\hline ChIn & $\begin{array}{c}\boldsymbol{R}_{\mathbf{0}}, \\
\mathbf{O h m} \cdot \mathbf{c m}^{\mathbf{2}}\end{array}$ & $\begin{array}{c}\boldsymbol{R}_{\mathbf{1}}, \\
\mathbf{O h m} \cdot \mathbf{c m}^{\mathbf{2}}\end{array}$ & $\begin{array}{c}\boldsymbol{C}_{\mathbf{1}}, \\
\boldsymbol{\mu} \mathbf{F} / \mathbf{c m}^{\mathbf{2}}\end{array}$ & $\begin{array}{c}\boldsymbol{R}_{\mathbf{2}}, \\
\mathbf{O h m} \cdot \mathbf{c m}^{\mathbf{2}}\end{array}$ & $\begin{array}{c}\boldsymbol{C}_{\mathbf{2}}, \\
\boldsymbol{\mu} \mathbf{F} / \mathbf{c m}^{\mathbf{2}}\end{array}$ & $\begin{array}{c}\boldsymbol{W}, \\
\mathbf{O h m} / \mathbf{c m} \mathbf{0 . 5}\end{array}$ & $\boldsymbol{Z \%}$ \\
\hline Without ChIn & 369 & 7475 & 2.5 & 10460 & 4.1 & 17822 & - \\
SA & 514 & 24701 & 1.2 & 57845 & 1.4 & 35871 & 69.8 \\
ОЛК & 573 & 10021 & 1.6 & 12282 & 1.2 & 106725 & 72.2 \\
LA & 444 & 9536 & 2.1 & 11713 & 1.3 & 114600 & 73.6 \\
PA & 642 & 17475 & 1.1 & 38754 & 1.0 & 97155 & 76.6 \\
SA+PA & 514 & 58253 & 0.5 & 161121 & 0.5 & 181333 & 91.1 \\
OLA+PA & 651 & 104261 & 0.3 & 265403 & 0.2 & 363112 & 95.1 \\
LA+PA & 526 & 137558 & 0.7 & 144782 & 0.4 & 246435 & 93.2 \\
\hline
\end{tabular}

These data allowed us to assume that CT steel with vapors of mixed inhibitors can be used in the interoperational protection of metal items. This conclusion is confirmed by field corrosion tests. The mixed inhibitors studied ensured complete protection of steel in these tests throughout the entire period of sample exposure (4 months) at the Moscow Corrosion 
Station. The first signs of corrosion under these conditions already appeared on the reference samples within a week after the start of the experiment.

It is important that the significant protective effects of mixed ChIn are due to the formation of very thin films on the surface. This follows from XPS data considered below (Table 4).

Table 4. The effect of steel treatment with ChIn vapors on the thickness of surface layers.

\begin{tabular}{cccc}
\hline \multirow{2}{*}{ ChIn } & \multicolumn{3}{c}{ Layer thickness $\boldsymbol{d}(\mathbf{n m})$} \\
\cline { 2 - 4 } & $\left(\mathbf{C H}_{\boldsymbol{x}}\right)_{\boldsymbol{n}} \mathbf{H}_{\mathbf{2}} \mathbf{O}$ & Adsorbed $\mathbf{C h I n}$ & $\mathbf{F e}_{\mathbf{2}} \mathbf{O}_{\mathbf{3}}$ \\
\hline SA+PA & 0.8 & 3.7 & 3.2 \\
OLA+PA & 1.2 & 4.2 & 3.7 \\
LA+PA & 1.0 & 5.3 & 5.5 \\
\hline
\end{tabular}

For steel samples that did not undergo heat treatment, three peaks were observed in the $\mathrm{C} 1 \mathrm{~s}$ electron spectrum: carbon from oil contaminants $\left(\mathrm{sp}^{3}\right)$ at $285.0 \mathrm{eV}$, carbon bound with oxygen of $\mathrm{OH}$ groups $(286.2 \mathrm{eV})$, and $\mathrm{CO}_{2}$ adsorbed from air $(288.7 \mathrm{eV})$. The spectrum of iron $\mathrm{Fe} 2 \mathrm{p}_{3 / 2}$ contained an intense peak corresponding to the metallic state and to the components of the mixed oxide $\mathrm{FeO} / \mathrm{Fe}_{2} \mathrm{O}_{3}$. The small fraction of iron oxide in the spectrum, as well as the presence of components corresponding to iron oxide in the $\mathrm{O} 1 \mathrm{~s}$ spectrum $(529.8 \mathrm{eV})$, indicate that an oxide film is formed with thickness $d$ not exceeding $1.6 \mathrm{~nm}$. Aside from it, the surface contained layers of adsorbed water $1.5 \mathrm{~nm}$ thick and organic impurities containing nitrogen and $\mathrm{CO}_{2}$.

Heating a steel sample to $120^{\circ} \mathrm{C}$ in the absence of a $\mathrm{ChIn}$ resulted in an increase in the oxygen content in the sample (from $26.99 \%$ to $40.56 \%$ ) and the fraction of oxide components in the spectrum of iron. The thickness $d$ of the oxide film increased almost twofold after heating $(3.6 \mathrm{~nm})$. The thickness of adsorbed water layer increased to $2.0 \mathrm{~nm}$ in this case.

Treatment of the metal with mixed ChIn vapors increased the intensity of the carbon peak related to the formation of adsorption films on steel. Unfortunately, the molecules of the ChIn studied contain no markers that would allow us assign the observed lines unambiguously. Therefore, the calculations were based on the fact that three layers are formed on steel surface: a layer of iron oxide $\mathrm{Fe}_{2} \mathrm{O}_{3}$, a layer of a ChIn with an equimolar ratio of the acid and $\mathrm{PA}$, as well as an organic layer containing carbon contaminants and water molecules $-\left(\mathrm{CH}_{x}\right)_{n} \mathrm{H}_{2} \mathrm{O}$.

$\mathrm{X}$-Ray photoelectron spectra obtained on samples treated in vapors of mixed ChIn were similar and mainly differed in the intensity of peaks. As an example, a description of the spectra of $\mathrm{C} 1 \mathrm{~s}, \mathrm{O} 1 \mathrm{~s}$ and $\mathrm{Fe} 2 \mathrm{p}_{3 / 2}$ electrons for a steel sample treated with OLA+PA vapors is given below (Figure 4). 

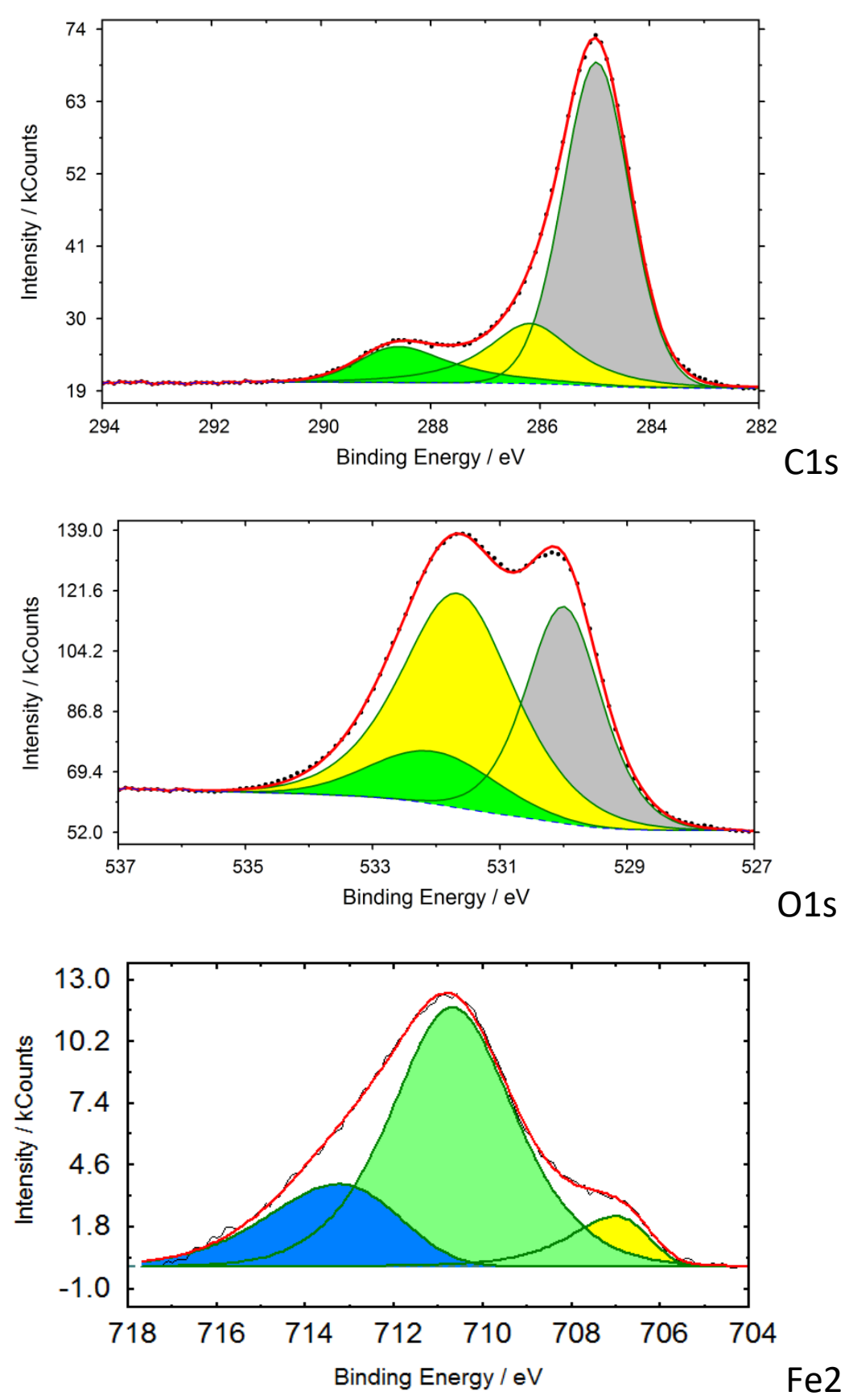

$\mathrm{Fe} 2 \mathrm{p} 3 / 2$

Figure 4. XPS spectra of $\mathrm{C} 1 \mathrm{~s}, \mathrm{O} 1 \mathrm{~s}$ and $\mathrm{Fe} 2 \mathrm{p}_{3 / 2}$ electrons of a steel sample treated with OLA + PA vapors.

The C1s spectrum of a sample exposed in vapors of this ChIn had no significant differences from the spectrum of samples treated without an inhibitor. The O1s spectrum could be decomposed into three components: the atoms of the element in iron oxide $(530.0 \mathrm{eV})$, the atoms that form the hydroxide layer $(531.5 \mathrm{eV})$, and the atoms bound to carbon $(532.2 \mathrm{eV})$. Three lines are also observed in the spectrum of $\mathrm{Fe} 2 \mathrm{p}_{3 / 2}$ electrons. One of these belongs to metallic iron $(706.8 \mathrm{eV})$ and the other two, to its oxidized (3+) state 
(710.8 eV, a satellite at $713.5 \mathrm{eV}$ ). Furthermore, adsorbed molecules containing nitrogen $(400.2 \mathrm{eV})$ were present on the surface.

The thicknesses of the adsorption layer of OLA+PA, oxide film and $\left(\mathrm{CH}_{x}\right)_{n} \mathrm{H}_{2} \mathrm{O}$ layer calculated from this spectrum were 4.2, 3.7 and $1.2 \mathrm{~nm}$, respectively (Table 4).

After exposure of a sample in SA+PA vapors, the thickness of the ChIn layer was slightly smaller, viz., $3.7 \mathrm{~nm}$. The thickness of the $\left(\mathrm{CH}_{x}\right)_{n} \mathrm{H}_{2} \mathrm{O}$ and iron oxide layers were 0.8 and $3.2 \mathrm{~nm}$, respectively, in this case.

Upon CT of samples in LA+PA vapors, the amount of carbon increased significantly (62.77\%), whereas the amount of iron decreased. Furthermore, the spectrum of iron contained no peak corresponding to the metallic state, which indicates the formation of a thick adsorption film on the sample surface. In this case, the layer thicknesses were calculated based on the oxide film rather than the metallic iron surface. The thickness of the adsorbed ChIn layer was $5.3 \mathrm{~nm}$, while those of the $\left(\mathrm{CH}_{x}\right)_{n} \mathrm{H}_{2} \mathrm{O}$ and iron oxide layers were 1.0 and $5.5 \mathrm{~nm}$, respectively.

The main inaccuracy in determining the thickness of ChIn surface films on a metal is associated with the assumption that the acid and PA are present there in equimolar ratio. However, calculations show that varying the ratio of the ChIn components in the adsorption layers leads to an error of no more than $\pm 0.5 \mathrm{~nm}$. This makes it difficult to compare the adsorption properties of the mixed CIN studied. However, it allows us to conclude that the thickness of surface layers on the steel, which are formed during its CT and provide a PAE, does not exceed a few nanometers.

\section{Conclusions}

1. One-hour treatment of steel with vapors of mixtures of higher carboxylic acids (stearic, oleic, linolenic) with polyamine $\mathrm{A}$ at $120^{\circ} \mathrm{C}$ results in the formation of nano-scale adsorption films with a pronounced protective aftereffect on its surface.

2. ChIn based on mixtures of higher carboxylic acids with polyamine A manifest a synergistic effect. The protective aftereffect of adsorption films formed by these mixtures considerably exceeds similar characteristics of films obtained by CT of steel by the components of these mixtures and is sufficient for the inter-operational protection of steel items.

\section{References}

1. P.D. Donovan, Protection of Metals from Corrosion in Storage and Transit, Chichester, Ellis Horwood Limited, 1986, 228 pp.

2. P.A. Schweitzer, Fundamental Metallic Corrosion: Atmospheric and Media Corrosion, New York, CRS Press, 2007, 721 pp.

3. A.A. Mikhailov, Yu.M. Panchenko and Yu.I. Kuznetsov, Atmospheric corrosion and protection of metals, 2016, Tambov, Pershina publishing house, 555 pp. (in Russian).

4. I.L. Rozenfel'd and V. P. Persiantseva, Inhibitors of atmospheric corrosion, Moscow, Nauka, 1985 (in Russian). 
5. P.A. Vinogradov, Preservation of engineering products, Leningrad, Mashinostroenie, 1986, 270 pp. (in Russian).

6. N.N. Andreev and Yu.I. Kuznetsov, Physicochemical aspects of the action of volatile corrosion inhibitors, Russ. Chem. Rev., 2005, 74, no. 8, 685.

7. S. Koehler and G. Reinhard, VCI containing package material - mode of functioning, Int. J. Corros. Scale Inhib., 2014, 3, no. 4, 286-306. doi: 10.17675/2305-6894-2014-34-286-306

8. N.N. Andreev and Yu.I. Kuznetsov, Volatile Inhibitors of Metal Corrosion. 1. Vaporization, Int. J. Corros. Scale Inhib., 2012, 1, no. 1, 16-25. doi: 10.17675/23056894-2012-1-1-016-025

9. D.M. Bastidas, E. Cano and E.M. Mora, Volatile corrosion inhibitors: a review, AntiCorros. Meth. Mater., 2005, 52, no. 2, 71-77.

10. N.N. Andreev and Yu.I. Kuznetsov, Volatile inhibitors of metal corrosion. II. Interaction of systems being protected with the environment and corrosion prevention conditions, Int. J. Corros. Scale Inhib., 2012, 1, no. 2, 146-153. doi: 10.17675/23056894-2012-1-2-146-153

11. D. Zhang, Z. An, Q. Pan, L. Gao and G. Zhou, Volatile corrosion inhibitor film formation on carbon steel surface and its inhibition effect on the atmospheric corrosion of carbon steel, Appl. Surf. Sci., 2006, 253, no. 3, 1343-1348.

12. N.N. Andreev and Yu.I. Kuznetsov, Volatile Inhibitors of Metal Corrosion. III. Principles and methods of efficiency estimation, Int. J. Corros. Scale Inhib., 2013, 2, no. 1, 39-52. doi: $10.17675 / 2305-6894-2013-2-1-039-052$

13. A.I. Altsybeeva, V.V. Burlov, N.S. Fedorova, T.M. Kuzinova and G.F. Palatik, Volatile inhibitors of atmospheric corrosion of ferrous and nonferrous metals I. Physical and chemical aspects of selection of starting reagents and synthetic routes, Int. J. Corros. Scale Inhib., 2012, 1, no. 1, 51-64. doi: 10.17675/2305-6894-2012-1-1-051$\underline{064}$

14. N.N. Andreev, O.A. Goncharova and S.S. Vesely, Volatile inhibitors of atmospheric corrosion. IV. Evolution of vapor-phase protection in the light of patent literature, Int. J. Corros. Scale Inhib., 2013, 2, no. 3, 162-193. doi: 10.17675/2305-6894-2013-2-3$\underline{162-193}$

15. A.Yu. Luchkin, O.A. Goncharova, N.N. Andreev and Yu.I. Kuznetsov, A new method for metal protection from atmospheric corrosion, Prakt. Protivokorroz. Zashch. (Practice of Corrosion Protection), 2017, no. 4, 7-12 (in Russian).

16. A.Yu. Luchkin, O.A. Goncharova, N.N. Andreev, Yu.I. Kuznetsov and N.P. Andreeva, Copper protection by treatment with vapors of low volatile inhibitors at elevated temperature, Korroz.: Mater., Zashch. (Corrosion: Materials, Protection), 2017, no. 11, 25-31 (in Russian). 
17. A.Yu. Luchkin, O.A. Goncharova, N.N. Andreev and Yu.I. Kuznetsov, Steel protection by treatment by vapors of octadecylamine, benzotriazole and their mixture at elevated temperature, Korroz.: Mater., Zashch. (Corrosion: Materials, Protection), 2017, no. 12, 20-27 (in Russian).

18. O.A. Goncharova, Yu.I. Kuznetsov, N.N. Andreev, A.Yu. Luchkin, N.P. Andreeva and D.S. Kuznetsov, A new corrosion inhibitor for zinc chamber treatment, Int. J. Corros. Scale Inhib., 2018, 7, no. 3, 340-351. doi: 10.17675/2305-6894-2018-7-3-5

19. O.A. Goncharova, A.Yu. Luchkin, Yu.I. Kuznetsov, N.N. Andreev, N.P. Andreeva and S.S. Vesely, Octadecylamine, 1,2,3-benzotriazole and a mixture thereof as chamber inhibitors of steel corrosion, Int. J. Corros. Scale Inhib., 2018, 7, no. 2, 203-212. doi: 10.17675/2305-6894-2018-7-2-7

20. O.A. Goncharova, N.N. Andreev, A.Yu. Luchkin, Yu.I. Kuznetsov, N.P. Andreeva and S.S. Vesely, Protection of copper by treatment with hot vapors of octadecylamine, 1,2,3-benzotriazole, and their mixtures, Mater. Corros., 2019, 70, no. 1, 161-168.

21. O.A. Goncharova, A.Yu. Luchkin, Yu.I. Kuznetsov and N.N. Andreev, Vapor=phase protection of zinc from atmospheric corrosion by low-volatile organic inhibitors, Korroz.: Mater., Zashch. (Corrosion: Materials, Protection), 2018, no. 8, 8-13 (in Russian).

22. O.A. Goncharova, A.Yu. Luchkin, N.N. Andreev, N.P. Andreeva and S.S. Vesely, Triazole derivatives as chamber inhibitors of copper corrosion, Int. J. Corros. Scale Inhib., 2018, 7, no. 4, 657-672. doi: 10.17675/2305-6894-2018-7-4-12

23. Yu. Kuznetsov, O. Goncharova, A. Luchkin, S. Vesely and N. Andreev, Vapor-phase protection of metals from atmospheric corrosion by low-volatile organic inhibitors, Eurocorr, 2018, Paper 121167.

24. D.A. Shirley, High-Resolution X-Ray Photoemission Spectrum of the Valence Bands of Gold, Phys. Rev. B., 1972, 5, 4709-4713.

25. M. Mohai, XPS MultiQuant: multimodel XPS quantification software, Surf. Interface Anal., 2004, 36, 828-832.

26. H. Scofield, Hartree-Slater subshell photoionization cross-sections at 1254 and 1487 eV, J. Electron Spectrosc. Relat. Phenom., 1976, 8, 129-137.

27. P.J. Cumpson and M.P. Seah, Elastic Scattering Corrections in AES and XPS. II. Estimating Attenuation Lengths and Conditions Required for their Valid Use in Overlayer/Substrate Experiments, Surf. Interface Anal., 1997, 25, 430-446.

28. M.C. Biesinger, B.P. Payne, A.P. Grosvenor, L.W. Lau, A.R. Gerson and R.S.C. Smart, Resolving surface chemical states in XPS analysis of first row transition metals, oxides and hydroxides: Cr, Mn, Fe, Co and Ni, Appl. Surf. Sci., 2011, 257, no. 7, 2717-2730. doi: 10.1016/j.apsusc.2010.10.051 